\title{
SONHOS E NOMES: AS CRIANÇAS GUARANI*
}

\author{
Paulo Humberto Porto Borges ${ }^{*}$
}

RESUMO: Este artigo tem como objetivo discutir como os grupos indígenas Guarani internalizam seu reko porã ("bom modo de proceder") entre suas crianças e constroem seus conceitos de infância e trabalho, no intuito de formarem o chamado guarani ete, ou seja, o(a) guarani verdadeiro.

Palavras-chave: Crianças. Indígena. Cultura. Trabalho. Guarani. Religião.

\section{DREAMS AND NAMES: GUARANI CHILDREN}

ABSTRACT: This paper aims at discussing how Guarani indian groups have their children internalize the reko porã ("good way of acting") and construct their concept of childhood and work, in order to form what they call the guarani ete, i.e., the true guarani.

Key words: Children. Native Americans. Culture. Work. Guarani. Religion.

* Neste texto, para grafar termos e expressões em idioma indígena, segui a convenção firmada pela Associação Brasileira de Antropologia (ABA), em 1953, não levando em conta, por isso, a flexão portuguesa de número e gênero. Fala-se, pois, em "os guarani" e não em "os guaranis".

** Professor do Curso de Pedagogia da Unioeste - Campus Cascavel. Atua desde 1990 junto a povos indígenas do Brasil na área de escolarização e formação de professores, em especial, junto aos grupos Guarani. Home-Page: www.djweb.com.br/historia. 
7 lgum tempo atrás, o guarani Luís Werá (cuja mulher se encontrava grávida) confidenciou-me que havia sonhado com a alma de seu futuro filho. A alma havia aparecido em um sonho e sussurrado que seu nome também seria Werá. Segundo Luís, isto é um bom sinal, por que este nome é um nome "forte", indicando que o meninozinho (Luís já sabe que seu filho será do sexo masculino, pois isto também lhe foi soprado pela alma) chegará sem problemas até a fase adulta, sendo imune a doenças e feitiços que porventura lhe atinjam ou lhe joguem. Entretanto, ele ainda aguardava com indisfarçada ansiedade a confirmação final do rezador. Pois, somente ele, o nhanderu $i,{ }^{1}$ poderia referendar ou não o nome que seu filho lhe contou em sonho. Afinal, cabe a ele, o rezador da comunidade, o sacerdote e profeta da palavra, a derradeira confirmação, que também lhe viria em forma de revelação.

$\mathrm{Na}$ concepção guarani, o que determina o nome é justamente a região de onde vem a alma da criança, não sendo jamais uma decisão arbitrária dos pais. É com base no "lugar de onde vem a alma" que o nome será constituído. E, ao saber sua origem, que sempre é dada pelo próprio filho por meio de sonhos, os pais também saberão suas qualidades e características individuais. Cada região do "zênite" possui determinados aspectos, assim como seus moradores. A origem do nome permite prever um pouco do percurso futuro dessa criança que ainda sequer nasceu, seus gostos, jeito de ser e possíveis caminhos a serem percorridos.

Entre os indígenas Mbya o processo de batismo do nome se atém fundamentalmente às mesmas normas; quando o menino não possui nome, está sujeito à cólera, raiz de todo o mal. "Somente quando se chame pelos nomes que nossos Pais da palavra lhe damos, deixarão de encolerizar-se.” Este nome é parte integrante da pessoa e é designado com a expressão 'ery mo' ã $a$ ', "aquele que mantém de pé o poder de dizer”. (Cadogan, 1992)

Segundo os guarani, é através das diversas regiōes celestes que as almas das crianças guarani chegam aos seus respectivos pais. Cada ponto possui nomes típicos representando a origem das crianças. Quem efetivamente dá o nome, batizando a criança, é o rezador da comunidade, sempre por intermédio de sonhos e visões. O antropólogo Curt Nimuendaju afirma algo semelhante: o rezador é quem determina "que alma veio a ter conosco". Esta pode ter vindo do "zênite" (espaço imediatamente acima de nós), onde vive Nãnderyquy, do oriente, morada Nandecy ou ainda dos longínquos domínios de Tupã, no ocidente. Ainda segundo Nimuendaju Unkel, alguns dos nomes mais usuais entre os homens guarani $\mathrm{Mbya}^{2}$ são: Tupäju, Jiguacañyjí, Avapoty (ava = homem/ 
poty = flor), Poyijú ("miçanga"), Avajupiá (jupiá = subir), Nimuendajú (muendá = fazer moradia), Mbaracábeí, Kuruayju (kuruay = sol), Wera’i ("pequeno brilho"), Karai Katu ("luz verdadeira") e Karai Mirim (karai = dono/senhor; mirim = pequeno). Entre as mulheres: Tacuapú (pú = troar), Tacuaverá (verá = brilhar), Tacuayvay (yvay = céu), Napycá (apycá = banco), Ara ("dia") e Kereju.

Os pajés são capazes de reconhecer, pelo nome, se a alma de seu portador veio do oriente, do zênite ou do ocidente; eu só o posso fazer nos pouquíssimos casos em que o nome se relaciona diretamente com as coisas próprias das divindades ali residentes. Tapejú se refere ao caminho para leste. Napycá vem do oeste, pois apyca é o banco em forma de canoa em que o deus ocidental do trovão, Tupã, viaja pelos céus provocando as trovoadas. Estas crianças de Tupã se distinguem ainda pelo cabelo menos liso que o usual, tendendo a ser ondulado. A alma de tais crianças está tão habituada ao uso do apycá que se deve, aqui na terra, fabricar-lhe um o quanto antes, no qual possam sentar; não o fazendo, é impossível que a alma se acostume aqui: ela retorna a Tupã e a criança morre. (Nimuendaju, 1987)

Em sua grande maioria são nomes que remontam a uma profunda religiosidade, relacionando-se quase sempre com a idéia de luz, desde o brilho ao troar do relâmpago, que são elementos fundamentais na mística guarani. Como também os diversos instrumentos utilizados durante a reza, como o maracá e o tacuapy ${ }^{3}$ Assim como é comum os cristãos nomearem suas crianças com referências bíblicas, como João ou José, as crianças guarani recebem no nome toda a carga espiritual do seu povo. Um arcabouço cultural que é repetidamente internalizado entre todos os membros do grupo - e, principalmente, durante a infância. É de se destacar que a força cultural desses povos reside basicamente nessa socialização, na qual se alternam experiências individuais e coletivas. Bartomeu Meliá afirma que toda a reconhecida persistência cultural guarani se encontra justamente neste trato com o sagrado. Somente o rezador poderá definir, por intermédio de seu contato com Nanderu, de onde vem a alma e, dessa forma, definir seu nome. Mas não só é permitido, como é esperado, o pai se adiantar ao rezador e entrar em diálogo por conta própria com a alma do filho. Entre os grupos guarani a experiência religiosa não é privilégio apenas dos rezadores ou sacerdotes, mas permeia toda a vivência comunitária em uma grande festa coletiva.

Ainda segundo os guarani, nos tempos antigos, a revelação do nome dava-se por volta dos 2 anos de idade, mas hoje em dia "tem alguns que não querem esperar mais e dão nome bem antes”. Com o 
advento do contato e a relação com o poder estatal, surgiram certas modificações em relação ao trato do nome, como, por exemplo, a necessidade sentida por alguns em receber um nome na língua do conquistador. Porém, visto mais a fundo, essa modificação é de caráter superficial, pois todos continuam com seus nomes revelados, ou nomes "verdadeiros". A diferença acontece em relação à importância que se dá ao nome "verdadeiro" e ao nome em português. Os guarani de Itariri ${ }^{4}$ relatam uma divertida história sobre este assunto, segundo contam: quando o cacique foi retirar a segunda via do documento de identidade de parte da comunidade, ele simplesmente esqueceu do sobrenome de várias famílias do grupo, e rebatizou-os todos como "da Silva" sem muita hesitação. E ainda hoje isso é motivo de troça entre os guarani de Itariri, não havendo qualquer tipo de represália em relação ao cacique, que também dá boas risadas quando esta história é relembrada. Afinal, este nome não é o nome revelado e, por pertencer ao mundo não-índio, possui pouco significado para o portador, podendo ser alterado sem maiores traumas. Ao contrário do nome verdadeiro, este sim fundamental para quem o carrega. Em relação ao batismo cristão "os guarani acham patético que o padre católico tenha que perguntar aos pais da criança como devem chamar seus filhos". Ainda segundo Meliá:

Não conferem a mínima importância, porém, a seus nomes cristãos, trocando com freqüência aquele recebido no batismo católico. Eles acham profundamente ridículo que o sacerdote cristão, que sempre se julga superior ao pajé pagão, pergunte aos pais da criança como esta se deveria chamar. Pretende que é padre e sequer é capaz de saber determinar o nome certo da criança! Daí o menosprezo do guarani ao batismo cristão e aos nomes portugueses. (Nimuendaju, 1987)

Os guarani prestam tanta importância ao nome que lhes foi revelado a ponto de, como último recurso em caso de doença de morte, o rezador rebatizar o doente por meio de rituais, a fim de que o mal não continue naquele corpo. Não é raro encontrarmos guarani que, ao saudá-lo pelo nome, ele finja não ouvir e faça questão de não atender. De imediato, outros nos avisam que o seu nome foi mudado, ele agora possui um novo e se voltará apenas a este. No antigo nome todas as doenças e os eventuais feitiços ficam aprisionados; é urgente esquecêlo o mais breve possível, a fim de que estes malefícios também desapareçam. O nome guarani "é um pedaço de seu portador, ou mesmo, quase idêntico a ele, inseparável da pessoa. $\mathrm{O}$ guarani não 'se chama' fulano de tal, mas ele 'é' este nome". 
Durante as grandes revoltas guarani no século XVII, na América Espanhola, a primeira preocupação era justamente renegar o nome em espanhol, adquirido por meio do batismo católico, e rebatizar-se:

Nos momentos de rebeldia anticolonial, o guarani tomava consciência de que seu nome espanhol o havia feito perder sua identidade, e é devida a isso a insistência dos xamãs em rebatizar, com o objetivo de encontrar para cada qual não apenas o seu nome, mas seu ser verdadeiro. (Meliá, 1993)

Entendendo a importância do nome para o percurso e a socialização do guarani, percebe-se que nesse grupo existe uma outra lógica em relação ao trato com a criança, que é quem, na verdade, escolhe o nome, ou melhor, traz o nome. É como se esta já viesse pronta, com suas vocações e possibilidades de ação. ${ }^{6}$ Dependendo de sua origem, de seu lugar celeste, ela poderá ser um grande rezador ou uma grande liderança política. Um bom caçador ou um homem com grandes roças. $\mathrm{O}$ fato de a criança escolher seu nome é também o fato de a criança escolher seus caminhos, à revelia dos pais, que têm como função apenas facilitá-lo na medida do possível, pois este já foi traçado anteriormente. O principal objetivo dos adultos guarani é possibilitar a formação do que eles chamam de guarani ete, ou seja, um guarani de verdade. Um adulto que possua todas as características de um bom homem guarani, que, entre outras, é ser religioso e avesso à sedução das coisas do mundo não-índio. Nos primeiros anos, a grande preocupação dos pais é assegurar o crescimento da alma, pois a criança ainda está fraca e vulnerável. Nesse período é comum os pais adotarem a criação de animais domésticos como galinhas e cachorros, que servem de anteparo protetor a qualquer malefício que venha do mundo exterior, como doenças e feitiços, pois os pais e os filhos ainda estão vulneráveis às maldades do mundo.

Como, por exemplo, o acontecido na comunidade guarani de Brakuí $^{7}$ em 1998, quando agentes de saúde municipais, preocupados com a quantidade de cachorros infectados com sarna e carrapatos, acharam por bem organizar uma aplicação geral de parasiticidas em todos os animais da comunidade. $\mathrm{O}$ resultado foi tão bom que, em pouco tempo, a cachorrada restabeleceu-se em cães saudáveis. Entretanto, nesse mesmo período, houve uma curiosa epidemia de gripe nas crianças da aldeia. De imediato, os mais velhos reuniram-se na casa de reza (opy guasu) e após horas de jeroky, ${ }^{8}$ referendaram que, como os cachorros ficaram muito fortes e bem de saúde, estavam imunes a doenças e feitiços, os quais, resvalando nestes, iam de encontro aos membros mais fracos da família. A saúde dos animais domésticos, no caso, cães, tornara vulneráveis as 
pessoas mais frágeis da comunidade, ou seja, as crianças. Pois, apesar de a criança ser uma "pessoa completa", ${ }^{9}$ ela inspira vários cuidados em seus primeiros anos de vida, em razão de sua fragilidade perante um mundo que é considerado ñeychyrögui arauka $i$ anguãema ("terrível e imperfeito"). Segundo Bartomeu Meliá:

A preparação para assegurar a vida e alma da criança começa já durante a gravidez. A mulher nesse tempo deve abster-se de toda comida pesada (banha, sal etc.) e lhe está tabuada a carne de um grande número de bichos do mato. (...) Assegurar o crescimento da alma da criança é a maior preocupação dos pais. Pais e filhos estão em "estado quente" e são numerosas as ameaças contra as quais se tem que defender. Continuam as proibições alimentares. $\mathrm{O}$ pai deve se abster de trabalhos pesados. Deve sobretudo evitar comportamento violento. Arco e flecha ou arma de fogo não deve usar nem para caçar. Mas pode pescar e colocar armadilhas. A criança mama quando quer, recebe o máximo de atenção, procura-se satisfazer suas necessidades. O período de lactência estende-se até os dois anos, ou às vezes mais. O desenvolvimento da alma, que em guarani é chamada "palavra", se considera completo quando a criança começa a pronunciar suas primeiras palavras. É então quando o "vidente", uma classe de pajés, talvez vá descobrir o nome religioso da criança, isto é, o nome daquela alma-palavra estabelecido já antes do seu envio para se assentar, como sobre um banquinho, no corpo da sua futura mãe. (Meliá, 1979)

Até os 3 anos, as crianças guarani são internalizadas culturalmente no reko ("costume") por todo o grupo social. É papel da sociedade como um todo a formação daquele indivíduo em um bom guarani, partilhando o seu dia-a-dia desde a interação do nascimento até a imersão completa na rotina cultural.

Após os primeiros anos, pequenos trabalhos, como buscar lenha ou mesmo cuidar dos irmãos e parentes menores, já se encontram no universo dessas crianças, que os desenvolvem de acordo com suas capacidades físicas e sexualidades. Com o tempo, estarão acompanhando os pais em seus afazeres rotineiros, sendo que, cada vez mais, a divisão sexual do trabalho se fará patente. No caso das aldeias do litoral paulista e carioca, as meninas guarani ajudarão a mãe na confecção e venda de artesanato durante as feiras municipais ou mesmo nas margens de BRs. Os meninos, quando um pouco maiores, acompanharão os adultos em suas incursões nas aldeias próximas, ${ }^{10}$ irão às cidades vizinhas e, provavelmente, começarão a explorar o palmito nativo existente em suas áreas. Porém, em todos os casos, a iniciação religiosa começa imediatamente após o assentamento da alma, ou seja, o nascimento. É comum encontrarmos nas opy guasú ("casa de reza”) diversas mães rezando, 
dançando e embalando seus filhos recém-nascidos ao som dos cantos e do maracá. A iniciação à religiosidade guarani é, certamente, a primeira socialização formal do grupo. Nesse sentido, não há limite de idade; talvez em virtude de a criança ser originária das regióes celestiais, ela esteja realmente muito mais próxima do que entendemos como sagrado. Mesmo assim, existem entre os guarani (em especial, entre os kaiowá, no Mato Grosso do Sul) certas práticas ritualizadas de iniciação dos jovens no mundo adulto, como o Kunumi pepy, momento no qual os jovens meninos recebem prescrições dos mais velhos (seus padrinhos) no sentido de "serem perfeitos" (imarangatuvarā) e preparam-se para a perfuração do lábio e a utilização do adorno labial denominado tembetá, sinal fundamental dos grupos guarani.

$\mathrm{Na}$ festa do Kunumi pepy, que pode durar vários dias, os padrinhos cuidam dos seus escolhidos e cantam seus deveres em relação aos jovens durante a festa de perfuração labial:

Kunumi ambojegua

Kunumi poty ambojegua

Kunumi ambojegua

Kunumi ku'akuaha ambojegua

Kunumi ambojegua

Kunumi ñée ambojegua

Kunumi ambojegua

Kunumi jeropapa ambojegua

Kunumi ambojegua

Kunumi aupeguáko ore

Kunumi(a) jasuka marane'y

Aupeguáko ore

Kunumi aupeguáko ore

Hëi Nengaju

Kunumi mba'ekuaa marane'y

Aupeguáko ore

Kunumi aupeguáko ore

Hëi Nengaju

Kunumi(a) jeguaka marane’y

Aupeguáko ore

Kunumi aupeguáko ore

Hëi Nengaju
Eu adorno o menino

Adorno a flor do menino

Eu adorno o menino

Adorno o cinto do menino

Eu adorno o menino

Adorno a palavra do menino

Eu adorno o menino

Adorno o relato da história do menino

Eu adorno o menino

Nós somos os que cuidam da alma dos meninos

Somos os que cuidam da essência

do jeito do bom proceder dos meninos

Nós somos os que cuidam da alma dos meninos Assim diz Nengaju

Somos os que cuidam do saber

do bom proceder dos meninos

Somos os que cuidam da alma dos meninos Assim diz Ñengaju

Somos os que cuidam da diadema do bom proceder dos meninos

Somos os que cuidam da alma dos meninos Assim disse Nengaju. (Chamorro, 1995) 
Neste puraheí ("canto") percebe-se toda a cautela que se tem na preparação do jovem em sua entrada para o mundo dos homens, que não é qualquer mundo, mas o mundo dos homens guarani. É necessário cuidar da alma, adornar ${ }^{11}$ a história e ensinar o bom proceder, pois somente com a sua plenitude, tanto religiosa como de sua origem (que se confundem em seus significados), é que será possível a continuidade do reko, que será possível a construção do guarani ete.

Sobre a importância desta imersão cultural, alguns rezadores kaiowá afirmam que os suicídios que vêm ocorrendo nas comunidades do Mato Grosso do Sul são, em parte, devidos à má formação das crianças guarani, pois estas não estão "adornadas" conforme os antigos. Em conseqüência, elas enfraquecem, entristecem e morrem. Nas palavras dos xamãs guarani:

Devido às crianças crescerem sem adornar-se, crescem tristes ("oñemyro") e "caem na corda" (referência aos enforcamentos). Quando as criaturas não são adornadas, elas crescem pensando somente em si, se esquecem dos donos do ser (...) é a tristeza, é crescer sem escutar mais a ninguém. Sozinha, sem as rezas e sem os versos dos velhos, a criatura cresce abandonada, à mercê do vento, perdida, fazendo coisas apenas para si mesma. (Chamorro, 1995)

Ainda sobre a necessidade de as crianças cresceram adornadas, Pa'i Paulito, um dos rezadores kaiowá mais respeitados e principal responsável pelas últimas festas de Kunumi pepy no Mato Grosso do Sul, profetiza “é certo, as criaturas que não são adornadas são como raízes doentes, não servem mais para semente".

Neste sentido, é importante percebermos que cada grupo indígena tem sua maneira de socialização interna, de acordo com seus padrões culturais e sua visão de mundo; o 'bom guarani' jamais seria um 'bom kaingang'. Cada povo indígena possui um ritmo próprio e uma partitura única, de acordo com suas experiências e seus percursos históricos; o que é louvado no 'bom proceder' guarani não é levado em conta em outros povos. Cada sociedade educativa constrói formas distintas de interação, com base em valores também distintos. Uma das primeiras coisas que uma criança guarani aprende é a importância das vivências místicas e a constante relação com o sagrado. Ao contrário de outros grupos que, por exemplo, privilegiam a virilidade e a disposição bélica de seus membros. Não existe um modo de ser indígena, mas, vários povos com seus modos específicos. Como nos alerta a antropóloga Aracy Lopes (apud Meliá, 1979) em relação à socialização da sociedade Xavante: 
Quando alcançam de nove a doze anos de idade os meninos deixam a casa de seus pais e passam numa "casa de solteiros", recebem alimentos que suas mães e irmãs lhes enviam, mas dormem sempre nessa casa. Espera-se que andem todos juntos, que dividam tudo entre si, que sejam recatados e que evitem o contato com as mulheres. Isto se prolonga por cinco ou seis anos durante os quais os meninos são formados, desenvolvendo as qualidades que nesta sociedade são prezadas como típicas de um verdadeiro homem: força, resistência física, agilidade, destreza, agressividade. Também é nessa época que aprende a confeccionar seus instrumentos de trabalho e de defesa e seus ornamentos. As técnicas de caça, agricultura e pesca, bem como atividades como a dança, o canto, a corrida de toras com buriti, são também intensamente desenvolvidas nesse período. (Meliá, 1979)

Ao contrário do senso-comum colonialista, adepto da uniformização cultural das chamadas etnias minoritárias, na qual todos os colonizados se parecem - “já viu um, viu todos” -, esses grupos afirmam suas ricas diferenças no processo de formação de suas crianças e em um futuro de bom proceder de acordo com os costumes de cada um, como almas belamente adornadas com sua história e reko.

Assim como o filho de Luís Werá se apresentou por intermédio de sonhos, o continnum desses grupos se apresenta nas revelações de seus rezadores mais tradicionais, como raízes que se prestam a boas sementes.

\section{Notas}

1. "Nosso pai pequeno”, termo guarani utilizado para designar o líder espiritual do grupo.

2. O povo guarani é subdividido em três grupos distintos, o nhandeva, o kaiowá e o mbya, como possuem entre si algumas diferenças culturais e lingüísticas.

3. Instrumento de percussão semelhante a uma taquara, que é utilizado para ditar o ritmo dos cantos durante a reza.

4. Aldeia guarani localizada no município de Itariri (SP), com aproximadamente 25 moradores.

5. Nimuendaju, p. 33.

6. A mesma palavra (mitãi) que designa "criança” também significa "criatura", sugerindo uma vida própria e origem divina.

7. Aldeia guarani localizada no município de Angra dos Reis (RJ), com aproximadamente 400 indígenas.

8. Dança religiosa guarani.

9. Em alguns casos, a criança vem reencarnada na alma de outro membro do grupo, isto é, já vem completa no sentido de possuir uma história anterior ao nascimento e, conseqüentemente, características já cristalizadas. E, em virtude disso, é tratada como se realmente fosse aquela pessoa já morta. Como nas palavras de Nimuendaju: "Em 1906 a irmã daquele infeliz, minha mãe adotiva Nimoá, teve um filho. Dias após o nascimento, levaram a criança para o rancho de meu padrinho Ponñochi, no Avari, onde se dariam a descoberta do nome e o batismo. Para este acontecimento se reuniu no rancho todo o bando de Joguyroquy, àquela época morando 
disperso; lá estava também o já mencionado Rapá, aquele que arrancara a ponta da flecha do quadril de Avajoguyroá. Ele tomou o pequeno nu em seus braços observando-o, sorridente, por todos os lados. De súbito, porém, devolveu-o à sua mãe e escondeu o rosto nas mãos, correndo para trás do rancho, onde se sentou a chorar amargamente, com o rosto virado para a parede. Passou um bom tempo até que, dominando-se, pôde informar aos companheiros que o cercavam o motivo de sua excitação. Mandou que trouxessem o pequeno e chamou a atenção de todos para o sinal vermelho-escuro que ele tinha no ombro e no quadril, lugares em que Avajoguyroá recebera as flechadas. Não havia o que duvidar: Avajoguyroá voltara à terra pelo ventre de sua irmã Nimoá, para rever sua mulher e conhecer a filha que só viera ao mundo depois de sua morte!". Nimuendaju, op. cit., p. 47.

10. Somente nos estados de São Paulo e Rio de Janeiro encontramos cerca de 14 aldeamentos guarani. E é muito freqüente o intercâmbio entre estas comunidades.

11. "Adorno (jegua) es una necessidade de todas las personas. Cuanda ellas están adornadas, hacen llover, hacen crecer. Las semillas son adornadas por la lluvia, las personas tambíen necesitan crecer, necesitan de adorno" (Chamorro, op. cit., p. 119).

\section{Referências bibliográficas}

BORGES, Paulo Humberto Porto. Ymã, ano mil e quinhentos. Campinas: Mercado de Letras, 2000.

CADOGAN, Léon. Ayvu Rapyta: Textos míticos de los mbya-guarani del Guaíra. Assunção: Biblioteca Paraguaya de Antropología, vol. 16, 1992.

CHAMORRO, Graciela. Kurusu Néengatu. Assunção: Centro de Estudios Antropológicos, 1995.

MELIÁ, Bartomeu. Educação indígena e alfabetização. São Paulo: Loyola, 1979.

. El guarani: Experiencia religiosa. Assunção: CEDUC-CEPAG, 1991. . El guarani conquistado e reducido. Assunção: Biblioteca Paraguaya de Antropología, vol. 5, 1993.

MEMMI, Albert. Retrato do colonizado precedido pelo retrato do colonizador. Rio de Janeiro: Paz \& Terra, 1977.

UNKEL, Curt Nimuendaju. As lendas da criação e destruição do mundo. São Paulo: Edusp, 1987. 